\title{
Major Salivary Gland Cancer cN2 TNM Finding V8
}

National Cancer Institute

\section{Source}

National Cancer Institute. Major Salivary Gland Cancer cN2 TNM Finding V8. NCI

Thesaurus. Code C132765.

Major salivary gland cancer with metastasis in a single ipsilateral lymph node larger than 3 $\mathrm{cm}$ but not larger than $6 \mathrm{~cm}$ in greatest dimension and ENE(-); or metastases in multiple ipsilateral lymph nodes, none larger than $6 \mathrm{~cm}$ in greatest dimension and ENE(-), or in bilateral or contralateral lymph nodes, none larger than $6 \mathrm{~cm}$ in greatest dimension and ENE(-). (from AJCC 8th Ed.) 